\title{
Perceptions of Indonesian Nurses Toward the Application of the Internet of Things in the Future
}

\author{
Taryudi Taryudi ${ }^{1}$, Linlin Lindayani ${ }^{2 *}$, Astri Mutiar ${ }^{2}$, and Heni Purnama ${ }^{2}$ \\ ${ }^{1}$ Faculty of Engineering, Universitas Negeri Jakarta \\ ${ }^{2}$ Department of Nursing, Sekolah Tinggi IImu Keperawatan PPNI Jawa Barat \\ ORCID
}

Linlin Lindayani: https://orcid.org/0000-0002-1569-4098

Corresponding Author:

aaaaaaaa; email:

linlinlindayani@gmail.com

Published: 7 February 2022

Publishing services provided by

Knowledge E

(c) Taryudi Taryudi et al. This article is distributed under the terms of the

Attribution License, which

permits unrestricted use and redistribution provided that the original author and source are credited.

Selection and Peer-review under the responsibility of the IVCN Conference Committee.
Abstract. In the healthcare industry, Internet of Things (IOT) based systems are utilized for phone care delivery, smart healthcare, smart health sensors and wearable technology, preventative systems, and distant monitoring. No studies have assessed nurses' perspectives of IoT applications in Indonesia. The purpose of this study was to identify health professionals' perspectives on future health and technology trends, to identify their readiness to adopt new health technologies, and to identify the use of loT technology in healthcare applications. This study was conducted using a descriptive and cross-sectional approach. Nurses with a Diploma III and at least one year of experience were selected from three different departments (medical surgical, pediatrics, maternity). About $76 \%$ of 350 nurses had little knowledge of loT technology and $95 \%$ said they do not keep up to date with loT publications. About $50 \%$ of nurses believed that loT technology will have a large impact on the health and education sectors. These results indicated that loT technology and informatics should be included in nursing education and further studies should be conducted to integrate technological trends into healthcare and nursing practices.

Keywords: perceptions, nurses, internet of things, healthcare

\section{Introduction}

The Internet of Things (IOT) system has shifted healthcare from a hub-based model to a more individualized model. The IoT technology applications in the e-healthcare sector are aimed at improving cost efficiency, dependability, and safety. In the healthcare industry, loT-based systems are utilized for phone care delivery, smart health care, smart health sensors and wearable technology, preventive systems and distant monitoring [1-3]. The Institute of Medicine (IOM) stated in 2010 that nurses should be prepared offer health services using electronic medical record, home networking devices, mobile applications, telehealth, IoT, and artificial intelligence. Healthcare workers will have new responsibilities in domains including smart health technology, remote monitoring, and biomedical equipment, according to futurists and international health organization executives [4,5]. 
Numerous studies on the use of loT technology in healthcare are currently underway, and they include linked home devices, biomedical applications, sensor technologies, monitoring, and smart and remote healthcare systems [6-9]. There is a strong correlation between the results obtained by intelligent rehabilitation systems (IRIS) and the outcomes achieved in clinical practice by physicians (Fan et al., 2014). Electronic medical records of physiological data acquired from sensors installed on remote patients utilizing loT technology were studied by [6]. A decision support approach was designed to record the doctor's categorization patterns, to create a new global classification schema, and to categorize newly diagnosed patient cases into facet categories. Biomedical signal collection systems can assess a subject's blood pressure, oxygenation, ECG, and EMG. This includes biological and patient monitoring applications [10]. Mobile technology for vital sign monitoring (blood sugar implants, biosensors) and electronic recording systems will undoubtedly expand the duties of physicians and nurses $[3,11,12]$. The Internet of Things (IOT) is intended to aid in monitoring patients, tracking human mobility, and responding to emergencies [12-14]. Vital indications will be collected via loT systems, which will enable interactive patient monitoring in collaboration with healthcare workers. Smart bed systems can be used to monitor hospital occupancy and if patients leave their beds. The use of web-based technologies allows nurses to monitor and follow up on patients more frequently, efficiently and safely. Patients can be tracked and alerted if they haven't taken their medications using loT technology such as home drug delivery systems, which can be connected to the Internet of Things (loT) [15]

Based on this data, health professionals' views on the impact of loT technology on the future of healthcare systems are critical to their technological readiness. There are no studies that have been conducted to assess nursing professionals' perspectives on the internet of things' application in Indonesia. The purpose of this study is to identify health professionals' perspectives on future health and technology trends, to identify their readiness to adopt new health technologies, and to identify the use of loT technology in healthcare applications.

\section{Methods}

\subsection{Study design}

This study was conducted using a descriptive and cross-sectional study. 


\subsection{Sample}

This study was conducted in West Java, Indonesia. A total of 1300 beds are available at this facility. Nurses with a Diploma III and at least one year of experience were selected. The sample was chosen on the basis of a predetermined criteria. The sample size and power were calculated. The study sample required a minimum of 100 nurses in bilateral correlation, with a type 1 error rate of ()$=0.05$ and an $80 \%$ confidence interval. The study sample consisted of 100 nurses from three different departments (medical surgical, paediatrics, maternity).

\subsection{Instrument}

loT technology knowledge, loT technology publications, opinions on the fields that loT technology will affect and where loT technology can be used [4]. This questionnaire featured questions about the impact of Internet of Things technologies on healthcare systems [11]. Due to the lack of robust and reliable instruments for assessing students' attitudes toward IoT, the researchers developed the questions based on a review of the literature and did not undertake psychometric evaluations. It was requested that the participants rate each issue between 0 (I disagree) and 10 (I completely agree) (I strongly agree).

\subsection{Data Collection}

The Institutional Review Board of the affiliated institution gave their approval to the study. The online survey was distributed to the nursing department for the purpose of conducting the survey. The respondents were informed about the study's privacy protocols through the use of a standardized framework, which helped to protect their personal information. It was necessary for each facility administrator to submit the online survey (which was conducted through an application platform) to the nursing staff before the results were released. Google was storing sensitive data during the procedure. Information was saved on a disk that could only be accessed by research team. The software prevented multiple access rights from the same e-mail address if the survey had already been completed. The survey took only a few minutes to complete and offered no reward. The data was gathered between June and August of 2021. 


\subsection{Data Analysis}

The data were inputted and analysed utilizing the SPSS (Statistical Package for the Social Sciences) software, version 21.0, using frequency, proportions, means, and standard deviations as the primary variables

\section{Results}

Participants were mostly female (77.5\%). Participants were mostly Sundanese (80\%), Javanese (12.5\%), and others (7.5\%). The participants ranged in age from 27 to 53 years, with the majority having a diploma degree. 34.2 percent of participants had work experience ranging from 11 to 15 years, and many of them worked in a chronic unit (32.5\%). $76 \%$ of 350 nurses had little knowledge of loT technology and $95 \%$ did not read update the loT publications (Table 1). Furthermore, 50 percent of nurses believe that loT technology will have the greatest impact on the health and education sectors. According to the majority of nurses, loT technology is most frequently used in mobile health applications and smart patient follow-up.

The nurse received the highest scores for the item "basic physical measurements using loT technology," followed by the item "offering remote care services using loT technology." "The Internet of Things will enable broad distant patient evaluation and management," and "IoT can track and evaluate chronic diseases remotely." They would have the lowest mean score $(3.82 \pm 0.76$ on the question "In the future, nurse's robot developed using loT technology will provide the best patient healthcare" (Table 2).

\section{Discussion}

To our knowledge, this is the first study to explore nurses' perspectives on loT and its potential in health care. Most of the nurses were unfamiliar with the Internet of Things (IOT) and did not keep up with the latest developments in loT technology [3]. Numerous applications can be utilized interchangeably or in conjunction with one another as a result of advancements and diversification in healthcare applications. Mobile health, $\mathrm{Al}$, and biotechnology are considered alongside loT technologies. The majority of participants from both departments agreed that loT technology will immediately effect health, education, genetics, and data security, and will directly affect medical and nursing procedures in particular. These students also stated that loT technology will be utilized in biomedical applications. loT technology will immediately impact future 
TABLE 1: Nurses' knowledge about loT's future (N: 100).

\begin{tabular}{|c|c|}
\hline Item & n (\%) \\
\hline \multicolumn{2}{|l|}{ Understanding the Internet of Things (IoT) } \\
\hline Yes, I do & $24(24)$ \\
\hline No, I do not & $76(76)$ \\
\hline \multicolumn{2}{|l|}{ Keeping up to date with loT publications } \\
\hline Yes, I do & $5(5)$ \\
\hline No, I do not2 & $95(95)$ \\
\hline \multicolumn{2}{|l|}{$\begin{array}{l}\text { Will loT technology have an impact on future nursing } \\
\text { applications? }\end{array}$} \\
\hline Yes, I do & $67(67)$ \\
\hline No, I do not & $18(18)$ \\
\hline I have no information & $15(15)$ \\
\hline \multicolumn{2}{|l|}{$\begin{array}{l}\text { The industries that will be most impacted by loT } \\
\text { technology? }\end{array}$} \\
\hline Health & $30(30)$ \\
\hline Education & $20(20)$ \\
\hline Industry & $35(35)$ \\
\hline I have no information & $15(15)$ \\
\hline \multicolumn{2}{|l|}{$\begin{array}{l}\text { loT technology will have the greatest impact on the } \\
\text { following industries? }\end{array}$} \\
\hline Smart follow-ups for patients & $16(16)$ \\
\hline Apps for mobile health & $30(30)$ \\
\hline eHealth and eCare & $10(10)$ \\
\hline Biomedical uses & $15(15)$ \\
\hline Wearable tech & $15(15)$ \\
\hline I have no information & $14(14)$ \\
\hline
\end{tabular}

TABLE 2: The nurses' view of the future of loT technology ( $N$ : 350).

\section{Items}

IoT technologies can remotely monitor and measure $5.43 \pm 1.34$ chronic conditions.

loT-enabled wearable and implanted sensors can collect $4.25 \pm 1.57$ physiological data from patients.

Remote care with loT reduces workload in health services. $6.11 \pm 2.82$

loT will reduce hospitalization times and increase home $5.77 \pm 1.04$ care services.

loT will make basic bodily measurements like blood sugar, $6.64 \pm 2.49$ heart rate, and ECGs easier.

loT will enable instantaneous communication between $5.07 \pm 1.92$ physicians, nurses, and patient family.

In the future, loT-powered robot doctors and nurses will $3.82 \pm 0.76$ treat patients.

The Internet of Things will reduce future health care costs. $4.26 \pm 1.45$

loT will enable broad remote patient diagnosis and $5.60 \pm 2.05$ treatment. 
healthcare practices in home care, chronic illness management, patient monitoring, and geriatric care [16]. Despite not keeping up with the latest health information, the nurses' perceptions matched the literature. This is a hopeful result for the nurses' future.

As mobile health systems grow increasingly popular, patient monitoring systems should evolve. Nurses can remotely monitor patients and provide simple interventions in an emergency. Thus, crucial follow-ups enabled by loT technology would assist nurses and other health workers in ensuring patient safety and providing healthcare services efficiently and effectively. Additionally, it will aid in the reduction of medical errors. The findings of this study indicated that nurse believe that Internet of Things (IOT) technology will have an impact on the future of nursing practices. This finding indicates that nurses were aware of the technologies that may impact their profession in the future and are prepared to adapt to emerging technology developments. In the future, patient-centered care will be the norm in healthcare companies. Home care will grow in the future. With the expansion of home care services, loT technology will enable more effective patient follow-up $[12,17,18]$.

Digital health has the potential to enable care to be structured around an individual's needs and desires, to improve coordinated care, and to facilitate the sharing of knowledge between patients and health care providers. As a result, the use of wireless devices to provide health care services outside of hospitals is now inevitable. Increased disease burdens place a strain on clinicians' ability to spend adequate time with each patient. Similarly, with a large patient population and an aging population, patient care, follow-up, and pharmaceutical applications consume a significant amount of time for health professionals. Remote care employing wireless technology reduces healthcare providers' workloads $[16,18]$.

The study's limitation was its generalizability. The findings are not indicative of nurses worldwide because they are based on a single hospital in Indonesia. Additionally, because only nurses were surveyed, the findings cannot be interpreted as providing insight into the application of loT across the entire healthcare system. The future application of the internet of things should be evaluated at many hospitals with input from customers and all healthcare workers.

\section{Conclusion}

This study explores the perception of nurses in clinical practice towards the internet of things. The nurse is unaware of the dynamics that will affect the world, health, medicine and nursing in the future, and can forecast the changes that may occur in the future, 
do not have adequate knowledge on loT technologies and applications. However, they are ready to take advantage of the technological changes that will affect healthcare systems. This represents the potential loT advances developed in various fields such as improving patient safety and reducing errors. These results indicated that loT technology and informatics should be involved in nursing education and further studies should be conducted to integrate technological trends into healthcare and nursing practices.

\section{Conflict of interest}

The authors declare that they have no conflict of interest.

\section{Role of funding source}

This work was supported by Ministry of Education and Culture 2021.

\section{References}

[1] Burmaoglu S, Saritas O, Kıdak LB, Berber IC. Evolution of connected health: A network perspective. Scientometrics. 2017;112(3):1419-38. https://doi.org/10.1007/s11192017-2431-x

[2] Ray P. understanding the role of internet of things towards smart e-healthcare services. Biomedical Research. 2017;28:1604-9.

[3] World Economic Forum. The future of jobs. 2016.

[4] Gonul Bodur, B. S. N., \& Yagmur Aydogan, B. S. N.. Biotechnology, health, nursing and future: Views of society in Turkey. International Journal of Caring Sciences. 2017;10(3):1554-62.

[5] Archibald MM, Barnard A. Futurism in nursing: Technology, robotics and the fundamentals of care. Journal of Clinical Nursing,. 2018;27(11-12):2473-80.

[6] Fu L, Li L. A smart decision making system for managing patient database. 2016:46_ 50.

[7] Yang P, Stankevivcius D, Marozas V, et al. Lifelogging data validation model for internet of things enabled personalized healthcare. IEEE Transactions on Systems, Man, and Cybernetics: Systems. 2018;48:50-64.

[8] Yang P, Xu L. The internet of things (IoT): Informatics methods for loT-enabled health care. Journal of Biomedical Informatics. 2018; 87:154-6. 
[9] Li S, Xu L, Zhao S. 5 G internet of things: A survey. Journal of Industrial Information Integration,. 2018;10.

[10] Yin YH, Fan YJ, Xu LD. EMG and EPP-integrated human-machine interface between the paralyzed and rehabilitation exoskeleton. IEEE Transactions on Information Technology in Biomedicine. 2012;16(4):542-9.

[11] Bodur G, Kaya H. The future of Turkish nursing 2050: Perceptions of nurses and nurse educators. International nursing review. 2017;64(4):511-9.

[12] Mieronkoski R, Azimi I, Rahmani AM, et al. The internet of things for basic nursing care-A scoping review. International journal of nursing studies. 2017;69:78-90.

[13] Broadbent E, Stafford R, Macdonald B. Acceptance of healthcare robots for the older population: Review and future directions. International journal of social robotics. 2009;1:319-30.

[14] Aktas F, Çeken C, Erdemli Y. Internet of things technology applications of biomedical field. Düzce Univ J Sci Technol. 2016;4:37-54.

[15] Islam SMR, Kwak D, Kabir MH, Hossain M, Kwak K. The internet of things for health care: A comprehensive survey. IEEE Access. 2015;3:678-708.

[16] Schartinger D, Miles I, Saritas O, et al. Personal health systems technologies: Critical issues in service innovation and diffusion. Technology Innovation Management Review. 2015;5(2):46-57.

[17] Qi J, Yang P, Min G, Amft O, Dong F, Xu L. Advanced internet of things for personalised healthcare systems: A survey. Pervasive and Mobile Computing. 2017;41:132-49.

[18] Farahani B, Firouzi F, Chang V, Badaroglu M, Constant N, Mankodiya K. Towards fog-driven loT eHealth: Promises and challenges of loT in medicine and healthcare. Future Generation Computer Systems. 2018;78:659-76. 